Indonesian Journal of EFL and Linguistics

Vol. 1 No. 2, 2016

eISSN: 2503-4197, pISSN: 2527-5070

www. indonesian-efl-journal.org

DOI: http://dx.doi.org/10.21462/ijefll.v1i2.8

\title{
Autonomous Learning for Proficiency Level in Foreign Language Development of Graduate Students
}

\author{
Dr. Halil Küçükler \\ School of Foreign languages, Balıkesir University, Turkey \\ e-mail:_hkucukler2@gmail.com
}

\begin{abstract}
:
Also called student-centred learning, autonomous learning is a multifaceted and self-motivated study skill that relates to a change in focus in the learning environment from the teacher to the student or from teaching to learning (Taylor 2000, p. 107). Its impact on linguistic competence has been investigated over time and the two have been found to be correlated. This survey was conducted in Ballkesir University in academic years of 2014-2015. The survey analyses graduate (Master of Arts) students' foreign language learning styles and strategies to find out to what extent they are autonomous. The aim of the study is to investigate the impacts of graduate students' proficiency attitudes on autonomous learning in foreign language learning. Two kinds of questionnaires were administered: the first one was learner autonomy survey questionnaire developed by Zhang and Li (2004), which was administered to investigate how autonomous the participants were in learning English as a foreign language. The second one was the perceptual learning style preference questionnaire (PLSPQ), developed by Reid (1987). The two questionnaires were administered to 600 graduate students enrolled in the Institutions of Social Sciences and the Institution of Health at Ballkesir University in the academic years of 2014-2015. Only 504 graduate students responded. Then it was announced that there would be two types of English YDS preparation courses for the participants enrolled at Ballkesir University, Institute of M.A programs. 30 participants applied to join the courses. The participants are assigned to two groups, as instructed and non-instructed on voluntary bases. The study involved the YDS test that measured the performance of the control and experimental groups to find out the differences. The study involved 15 sample YDS tests that were
\end{abstract}


administered after every two weeks of instructions. Before the training commenced, there were some preliminaries that were being applied to determine the advancement in the level of proficiency and the level of trainees. The results indicate that the male graduate students from both groups performed better than the female learners. The results also reveal that the control group scored a mean of 38 , 86 while the experimental group recorded 38, 06 in the first test. Throughout all tests, the experimental group only scores a few points less. The ultimate YDS (The formal Proficiency Exam) score was (control group= 48; experimental group $=47$ ), which is almost the same. There is no meaningful difference between the control and experimental group.

Keywords: autonomous learning, language learning style, proficiency, EFL

\section{INTRODUCTION}

There is a growing significance of foreign language in education. In particular, the importance of English in Foreign Language learning has been widely accepted in recent years and the English language is now well established as an international language. As a result of the growing significance of foreign language learning, learning autonomy has equally been a demand for foreign language learning. Learning autonomy refers to the ability of the learner to set goals for personal learning. The learner is also held responsible for his learning through the proper taking off charge and responsibility of learning. However, the teacher creates and maintains the learning environment.

The learning environment should support the learning of the students. Graduate scholars in different universities in Turkey are mandated to pass proficiency exam (YDS), failure to which they cannot proceed with their education. This can be frustrating and hence helping to solve failure in YDS exam can be of great importance to the scholars. For this reason, this research advocates that if scholars can embrace autonomous learning after university graduation, they are more likely to overcome the problems.

This paper covers research on the impact of autonomous learning on graduate students' proficiency level in foreign language learning. Therefore, the research paper entails methods, design, procedure, informants, as well as measuring tools that have been used in the evaluation of the process. Additionally, the research paper contains the level of autonomy required in learning a foreign language for a learner to become autonomous through self-instruction. Lastly, the research paper provides solutions as to whether the graduate learner training will improve the level of language proficiency in exams be it YDS or foreign.

\section{LITERATURE REVIEW}

\subsection{Learner Autonomy}

Autonomous learning sometimes referred to as learner-centred or flexible learning is a complex concept and therefore does not have a precise definition (Little 2004). It is generally associated with the change in focus in classroom learning from the 
teacher to the learners. MacDougall (2008, p. 224) simply defined autonomous learning as a type of learning that is characterized by "personalization, selfdirectedness, and less dependency on the educator for affirmation, and which therefore enhances, rather than hinders, the capacity for constructive collaborative participation in the learning process". Self-directed learning is every important because it helps achieve effective engagement or quality participation in the learning process. It means that the learner is empowered to re-construct what he/she already knows or believes into a system of beliefs, conceptualizations, values, as well as forms of reasoning which are characteristic of mature cognitive development.

Holec (1981, p. 3) provided a more comprehensive definition of learner autonomy in the context of a university language learner, describing it as the ability to take control of one's learning and responsibility for all decisions regarding all aspects of the learning, including: determining the learning objectives; defining the learning content as well as progressions; "selecting methods and techniques to be used; monitoring the procedure of acquisition properly speaking (rhythm, time, place, etc.)"; and evaluating or reflecting on what has been acquired. Holec is one of the earliest contributors to this field of autonomy in language learning. The author later summarized the definition of learner autonomy as "the ability to take charge of one's own learning" (Holec 2001, p. 48). Holec's perspective on the definition of learner autonomy is shared by Dickson's (1987), who defined it as "a situation in which the learner is totally responsible for all of the decisions concerned with his or her learning and implementation of those decisions" (cited in Gardner \& Miller 1996, p. 6).

From these definitions, autonomous learning is noted to be characterized by learner independence and learner taking greater responsibility for his/her learning, with the help of the teacher. Taking responsibility in this case means taking ownership, fully or partially, of the many learning process, including; setting learning objectives, selecting learning methods, as well as evaluating the learning process (Yan 2012, p. 558), which were traditionally the roles of the teacher. This means that the learner is helped and encouraged to assume maximum amount of responsibility for what he/she wants to learn as well as how to learn it.

\subsection{Importance of Proficiency}

The importance of language proficiency for improving educational performance through enhanced communication can never be over accentuated (Ludo \& John, 1992). It has been observed that students who portray difficulties in language proficiency may not function effectively, not only in the language related field, but also in other academic fields. When language proficiency of an individual is high, it consequentially improves the academic performance of such an individual. Likewise, an individual with low language proficiency demonstrates low academic performance. In a study conducted by Yushau (2015) focusing on the importance of English language proficiency in the performance of Mathematics, he concluded that individuals with high English proficiency concurrently demonstrated high performance in Mathematics. 
In a case where academic instructions are given using a language where a learner is less proficient, the learner faces the dual challenge of having to learn a foreign language, while concomitantly learning content from another discipline through the second language (Ludo \& John, 1992). This can considerably slow down, or at times totally impair the learning of the target subject where the foreign language is the medium of learning. Notably, English second language learners often have been considered less competent in academic related field in countries where English is the native language partly because of the challenges they encounter while using English as a medium of learning other academic disciplines (Yushau 2015).

Mastering proficiency in a given language is important as it allows an individual to effectively communicate using that language (Richard \& Eunice 1995). Communication is essential in various aspects of life, right from personal life to corporate life. In an organization setting, language proficiency enhances good communication which in turn is a vital tool in enhancing productivity and building a strong working relationship among one's colleagues and at various levels of the organization (Ana 2005). Individuals who invest time in building their language proficiency often deliver clear instructions.

Clear instructions and communication, in turn, enhances the level of trust among one's peers and morale in general. In contrast, poor language proficiency often leads to poor communication. In a case where an individual poorly communicates, especially within a context of an organization, the staff often become unmotivated and may at times question their abilities to perform the required tasks. Moreover, language proficiency enhances the employability of an individual (Ludo \& John 1992). An individual with excellent command of a language in which an employer is targeting has got a greater chance of being employed than an individual with low language proficiency in the target language. According to Ana (2005) high powered business executives often hire language consultants to coach them on how to effectively communicate.

\subsection{Relationship between Autonomous Learning and Language Proficiency}

In trying to promote learner autonomy, it is essential to consider not only social educational contexts, but also the characteristics of every student. Based on some previous studies, it is assumed that international students already possess a certain degree of autonomy in learning, but each student is different and therefore teachers should consider different approaches in promoting autonomy. Considering English as a Foreign Language (EFL) in an environment such as China, getting a high score in an English test seems to be the indicator of good achievement. Students are therefore very keen to get high scores in exams, which quite often determine their fate since the examination is the centre of ethos about education in their surrounding society (Cheng 1996). Due to this factor, learners tend to study outside their classes, as well as in the classes in order to achieve good English proficiency. This is to say students strive to take responsibility for their own learning so as to obtain high and good scores in tests if they want to be academically fitful in an exam-oriented education system (Zhe 2009). This shows that students' successes in foreign 
language tests in such societies are related to their learning autonomy (Wenden 1998).

A research done in Japan investigated the relationship between autonomy and language proficiency in the country. In this research, a report issued by the Society for Testing English Proficiency (STEP) in Japan indicated that there is a relationship between the degree of learner autonomy and the test scores in the examinations (STEP 2006).

\section{RESEARCH METHODOLOGY}

\subsection{Participants}

This study was conducted with graduate students enrolled at the institutes for MA programs at Balıkesir University. The Institutes have a total of 1500 enrolled students presently. The questionnaires were attached and mailed to all the students. The subjects were informed that there would be two types of program for the preparation of YDS exam. Detailed information was given about the two types of courses. Only 504 students responded out of the target of 600.30 students applied to join the courses. After the results of proficiency test which the subjects took at the beginning of November in the academic years of 2014-2015, two groups were selected for this research. 15 students wanted to take face to face course and the other 15 students wanted to study in the autonomous group. The case study continued for six months.

\subsection{Instrument}

\subsubsection{Questionnaires}

Considering the major objectives in the questionnaire, to investigate autonomous learning of graduate learners in English, the questionnaires sought to find out the attitude of learners about learning the language before the actual study.

\subsubsection{Learner Autonomy Questionnaire}

The questionnaire was surveyed questionnaire. It was student autonomy survey that was developed by Li and Zhang (2004). It was administered to determine the rate at which the learners were learning English as a foreign language. Student's autonomy survey was administered to help determine the participant personal activities in learning. It also helps to determine how it is used in learning The English language. The questionnaire has five major parts. These include learner's awareness, selfefforts, wider autonomous activities, self-esteem, and application of reference materials, motivation and use of technology in learning.

\subsubsection{The perceptual learning style preference questionnaire}

The Perceptual Learning Style Preference Questionnaire (PLSPQ) was developed by Reid (1987). The questionnaire has two parts. These include the role of the learner and the role of the teacher. 


\subsubsection{Strategy inventory for language learning SILL (Oxford, 1990)}

Strategy Inventory for Language Learning was given to the participants of the English language. The questionnaire covered fifty items. The participants were asked to arrange for their use of the strategy on the other point Liker. This scale consists of " never" or 'almost never'. The purpose of conducting the questionnaire was to help in identifying the language learning strategies as well as learning styles that are used by the graduate students in YDS examination. The learners' strategies, as well as learning styles, were analysed under the named titles, Memory Strategies, Cognitive Strategies, Compensation Strategies, Meta-cognitive Strategies, Affective Strategies and Social Strategies.

\subsubsection{Sample YDS exam and syllabus}

Prior to conducting the research, the topics of the unit for both the autonomous group as well as the investigational group were organized and the treatment for the experimental group was designed. At the beginning of November, the training of courses started. For every week, for eight hours, vocabulary- grammar-reading topics were taken care of in the experimental group. In addition to this, a sample YDS was employed every two weeks. And their scores were analysed and compared to see the progress.

\subsubsection{Proficiency test}

Before the training commenced, there were some preliminaries that were being applied to determine the advancement in the level of proficiency and the level of trainees. Throughout the course, learners had to capture two times in each month for proficiency tests. In the last three months, the experimental group took sample tests weekly. In total, the participants took 15 sample YDS tests. The last exam was formal YDS exam in April in the second term of 2015.

\subsubsection{Foreign language proficiency course}

For the preparation for the proficiency test, the students were exposed to grammatical work, reading skills and vocabulary. Lessons of the experimental group were the usual regular lessons in the classroom. On the other hand, the control group took studies at personal levels using basic learning strategies.

\subsection{Data Analysis}

\subsubsection{Data collection procedures}

Following the administration rules as well as regulation, the required permission was taken from the rector of the institution. It was ethically required to ask permission before administering the questionnaires, and this was obtained from the ethics board of Istanbul University. Additionally, the participants were also kindly asked and informed about their ethical rights pertaining to the study.

\subsubsection{Data analysis procedure}


Primary data was obtained from the questionnaires. The given sample of the exam data was analysed quantitatively using the statistical methods of packaging. The measure of central tendency was taken and calculated for the items recorded.

\section{FINDINGS}

There are many ways in which students engage in autonomous learning. Each of these ways include where students take their own initiative to learn, other than just depending on the teacher. Some of these include, taking notes and making summaries during lessons, practicing English, using the library, attending seminars, and using audio-visual materials. The mostly used strategy among all is making notes and summary of the lessons.

The results revealed that the participants are not fully autonomous learners, that is, they partly engage in autonomous learning, but also depend on their teachers. It was clearly seen that the participants are dependent on the teacher. Only $25 \%$ of the students believe that a lot of learning can be carried out without a teacher. The results revealed the fact that the graduate students cannot pass their proficiency test without the help of the teacher and thus, they are not fully autonomous learners.

To test the students' proficiency the YDS test was administered. This measured the performance of the control and experimental groups to find out the differences. The study involved 15 sample YDS tests, administered after every two weeks of instructions. The results indicated that the male graduate students from both groups performed better than the female learners (See Table 1).

Table 1: The group statistics of the results of proficiency exam after the study $*=\mathbf{P}<\mathbf{0 ,}, 05$

\begin{tabular}{|l|l|l|l|l|l|l|}
\hline $\begin{array}{l}\text { (First Score) } \\
\text { Gender }\end{array}$ & $\mathrm{N}$ & $\mathrm{M}$ & Std. Dev. & Df & $\mathrm{t}$ & $\mathrm{p}$ \\
\hline Male & 257 & 47.77 & 14.150 & 502 & 2.561 & .772 \\
\hline Female & 247 & 44.68 & 12.841 & & & \\
\hline
\end{tabular}

The male graduate students recorded 47.77 while the female students scored 44.68. In addition to that, a comparison of the experimental and the control group showed that the control group performed better.

Table: 2. Complete Group Statistics of all results of the sample YDS test scores

\begin{tabular}{|l|l|l|l|l|l|l|l|}
\hline Groups & N & Mean & $\begin{array}{l}\text { Std. } \\
\text { Dev. }\end{array}$ & df & t & P \\
\hline 1. First YDS Sample T. S & 15 & 38.06 & 9.07 & 28 & -0.45 & 0.65 \\
\cline { 1 - 4 } Experimental Group & 15 & 38.86 & 8.34 & & 28 & -.251 & .803 \\
\hline Control Group & 15 & 37.83 & 9.34 & & & \\
\hline 2. Prior Exam Scores & 15 & 39.33 & 8.88 & & \\
\cline { 1 - 1 } Experimental Group & Control Group & 3)Sample Test
\end{tabular}




\begin{tabular}{|c|c|c|c|c|c|c|}
\hline Experimental Group & 15 & 37.93 & 9.03 & \multirow[t]{2}{*}{28} & \multirow[t]{2}{*}{-.251} & \multirow[t]{2}{*}{.803} \\
\hline Control Group & 15 & 38.73 & 7.93 & & & \\
\hline \multicolumn{7}{|l|}{ 4) Sample Test } \\
\hline Experimental Group & 15 & 38.86 & 8.374 & \multirow[t]{2}{*}{28} & \multirow[t]{2}{*}{-.218} & \multirow[t]{2}{*}{.829} \\
\hline Control Group & 15 & 39.53 & 8.339 & & & \\
\hline Experimental Group & 15 & 39.86 & 8.927 & \multirow[t]{2}{*}{28} & \multirow[t]{2}{*}{-.729} & \multirow[t]{2}{*}{.472} \\
\hline Control Group & 15 & 42.06 & 7.535 & & & \\
\hline \multicolumn{7}{|l|}{ 6)Sample Test } \\
\hline Experimental Group & 15 & 41.00 & 9.063 & \multirow[t]{2}{*}{28} & & \multirow[t]{2}{*}{.248} \\
\hline Control Group & 15 & 44.46 & 6.885 & & .1 .18 & \\
\hline \multicolumn{7}{|l|}{ 7)Sample Test } \\
\hline Experimental Group & 15 & 41.73 & 8.639 & \multirow[t]{2}{*}{28} & \multirow[t]{2}{*}{-.432} & \multirow[t]{2}{*}{.163} \\
\hline Control Group & 15 & 45,86 & 7,099 & & & \\
\hline \multicolumn{5}{|l|}{ 8)Sample Test } & & \\
\hline Experimental Group & 15 & 41.73 & 9.230 & \multirow[t]{2}{*}{28} & \multirow[t]{2}{*}{-.920} & \multirow[t]{2}{*}{.366} \\
\hline Control Group & 15 & 44.60 & 7.780 & & & \\
\hline \multicolumn{7}{|c|}{ 9)(Mid-term) Sample T } \\
\hline Experimental Group & 15 & 42.06 & 9.654 & \multirow[t]{2}{*}{28} & \multirow[t]{2}{*}{-.334} & \multirow[t]{2}{*}{.741} \\
\hline Control Group & 15 & 43.13 & 7.726 & & & \\
\hline \multicolumn{7}{|l|}{ 10)Sample Test } \\
\hline Experimental Group & 15 & 42.26 & 9.572 & 28 & -.902 & .375 \\
\hline Control Group & 15 & 45.26 & 8.614 & & & \\
\hline 11)Sample Test & & & & & & \\
\hline Experimental Group & 15 & 42.80 & 10.303 & 28 & -.861 & 397 \\
\hline Control Group & 15 & 45.86 & 9.171 & & & \\
\hline 12)Sample Test & & & & & & \\
\hline Experimental Group & 15 & 43.60 & 10.854 & 28 & -.863 & .395 \\
\hline Control Group & 15 & 46.66 & 8.457 & & & \\
\hline 13)Sample Test & & & & & & \\
\hline Experimental Group & 15 & 44.66 & 11.049 & 28 & -.527 & .602 \\
\hline Control Group & 15 & 46.60 & 8.918 & & & \\
\hline 14)Sample Test & & & & & & \\
\hline Experimental Group & 15 & 45.26 & 11.485 & 28 & -.614 & .544 \\
\hline Control Group & 15 & 47.53 & 8.517 & & & \\
\hline 15) Final Sample Te & & & & & & \\
\hline Experimental Group & 15 & 44.46 & 10.868 & 28 & -.117 & 908 \\
\hline Control Group & 15 & 44.86 & 7.576 & & & \\
\hline 16)YDS Exam & & & & & & \\
\hline Experimental Group & 15 & 47.25 & 11.065 & 28 & -.217 & .830 \\
\hline Control Group & 15 & 48.03 & 8.594 & & & \\
\hline
\end{tabular}

Considering Table 2 statistics, it is noted that the first YDS sample scores of experimental and control groups are close to each other. The mean of the experimental group is 38.06 and the mean of the control group is 38.86 which are 
very close to each other. As for the first YDS sample score prior to Exams, the means of the control group and the experimental group are slightly different; 39.33 for the control group, which is slightly higher than that of the experimental group (37.83). Five more sample tests were administered until the mid-term exam and the variance between the control and experimental vary slightly, except the sample score just before midterm which varies by 2.87 .

The means of the experimental group and the control groups in the first three months are shown in Table 2 and Table 3. Throughout all tests, the experimental group only scored a few points less. The ultimate YDS (The formal Proficiency Exam) score was (control group $=48$; experimental group $=47$ ), which is almost the same.

That implies that despite using different techniques during the instruction period, the students' performance is similar, and therefore is no significant difference between the YDS test results between the two groups. At the beginning of the course, the mean of the first sample YDS score of the experimental group is 38.06 and 38.86 for the control group. The mean of the mid-term sample YDS score of the experimental group is 42.06 and 43.13 for the control group. It is observed that the means of some scores moved from 38.46 to 42 and 43 . The mean of the last formal YDS exam of the experimental group is 47.25 and the mean of the control group is 48.03.

Table 3: The first sample, mid-term and the last YDS scores

\begin{tabular}{|c|c|c|c|c|c|c|}
\hline Groups & Number & Mean & $\begin{array}{l}\text { Std. } \\
\text { deviation }\end{array}$ & df & $\mathbf{t}$ & $\mathbf{P}$ \\
\hline $\begin{array}{l}\text { 1)First YDS Sample } \\
\text { Test } \\
\text { Experimental Group } \\
\text { Control Group }\end{array}$ & $\begin{array}{l}15 \\
15\end{array}$ & $\begin{array}{l}38.06 \\
38.86\end{array}$ & $\begin{array}{l}9.074 \\
8.348\end{array}$ & 28 & -0.65 & 0.65 \\
\hline $\begin{array}{l}\text { 9) (Mid-term) Sample } \\
\text { Test } \\
\text { Experimental Group } \\
\text { Control Group }\end{array}$ & $\begin{array}{l}15 \\
15\end{array}$ & $\begin{array}{l}42.06 \\
43.13\end{array}$ & $\begin{array}{l}9.654 \\
7.726\end{array}$ & 28 & -.334 & .741 \\
\hline $\begin{array}{l}\text { 16) YDS Exam } \\
\text { Experimental } \\
\text { Group } \\
\text { Control Group }\end{array}$ & $\begin{array}{l}15 \\
15\end{array}$ & $\begin{array}{l}47.25 \\
48.03\end{array}$ & $\begin{array}{l}11.065 \\
8.594\end{array}$ & 28 & -.217 & .830 \\
\hline
\end{tabular}

It is clearly seen in Table 2 that the means of the experimental group are 38.06 for the first sample test, 42.06 for the mid-term sample test and 47.25 for the final Exam. Conversely, the means of the instructed group are 38.86 for the first sample test, 43.13 for the mid-term sample test, and 48.03 for the formal YDS. The only difference in proficiency development between the instructed and non-instructed EFL is that the latter has a higher mean score and standard deviation than the noninstructed. However, the difference in the mean is very small as it ranges from 0.1 to 2.0. For instance, the difference in scores of the first sample test for both the control 
group and the experimental group is 0.8 , for the Mid-term Exam is 1.07 and that of the Final Exam is 0.78 .

The varying differences could be explained in that in the first study, the students admitted using the same individual techniques to strengthen their language skills. Some techniques used by many students included watching English language movies, reading newspapers, using the internet, making notes and studying on their own. Despite being on different instructional groups, the students demonstrated their efforts in learning the language. The performance is justified by the final YDS results that indicate that the experimental group scored 47.25 while the control group is 48.03. A difference of less than one point shows that the performance is similar. In other words, the difference has no significance.

\section{DISCUSSION}

From the results, it is apparent that learners can employ varying autonomous levels during learning. Moreover, the results also indicate that during different periods of students' learning, different levels of autonomy can be engaged, probably as students prepare for exams and thus need to do more studies on their own. Based on the first sample YDS exam it is observed that the mean score was 37.93, which improved to 42.06 towards the end of the final exam. This indicates that the overall improvement of the learners during these two periods is 4.13 which is a substantial improvement. During the final sample YDS test, it is observed that the mean has also increased to 44.46 from 38.06 in the first YDS score test. In this case, an increment of two points is realized from the mean score obtained in the second sample YDS exam. Moreover, in the YDS exam results, the mean score is 47.25 which is an increment of 2.79 in the mean score. Probably during the first YDS score test. Students relied more on teachers and as Exams neared, they became more autonomous.

The standard deviation is also increasing indicating that there is an improvement in autonomous. The first sample test had a standard deviation of 9.035 but during the mid-term test, the standard deviation increased to 9.654. This resulted in an increment of 0.616 . When the final sample test was administered, it is noted that the standard deviation further increases to 10.868. This implies that there is an increment of 1.214 from the mid-term sample test. The increase in the standard deviation, in this case, is an indicator that there is a large positive variation in the means during the first three periods of the exam. This is proof that learners can improve their language proficiency through autonomous learning.

\subsection{Pedagogical Implications}

The results from this study will have several pedagogical implications on various stakeholders, namely teachers, students, teacher development experts and policy makers, school heads, education researchers and learning institutions at large, among other relevant stakeholders (Sun 2010, p. 867). Implications on teachers imply that teachers should step up to ensure that students learning a foreign language have an easy time understanding and applying the new language. Some of the strategies they can use include; contrastive analysis, helping students acquire vocabulary, helping 
and encouraging students to read and write, and correcting their writing. Students on the other hand should improve their listening skills by being attentive and practicing what they are taught, use the dictionary more often, engaging in social activities, and practice reading and writing on their own. Other stake holders, such as the school heads and education experts should provide and allow appropriate training for teachers, provide modern learning equipments, such as audio-visual cues, and ensuring safe and conducive learning environment for learners and teachers.

\section{CONCLUSION}

The techniques amassed enormous and extreme significant impact on the students, especially in the non-instructed class. These students engaged in learning the foreign language by themselves and accrued confidence and self-esteem. 'Complete understanding and persistence come with sole effort and hunger to grow within a student' (Grishaf, 2006). The autonomy based learning techniques show the importance of the teacher towards the learners' understanding of language. The tutor therefore is not to be absent, but present only to identify students' strengths and weaknesses and properly correct the learners' errors. Although failing students refuse to shift the blame to the teachers, the teacher should demonstrate and thoroughly explain the technique of mastering the language to them. The best approach to learning a foreign language is the use of instructive technique and methodology as evidenced by the result of the final test.

Learners can easily improve their language proficiency through autonomous learning (Abbasian \& Hartoonian 2014). Throughout the study, it is ascertained that there is no much difference between the experimental group and the nonexperimental group. In the first sample test, the scores of 38.06 and 38.86 had a negligible difference of 0.8 . However, as exams approached towards the end of the term, scores in experimental and non-experimental scores expanded. The scores of the test applied at the end of the first term were 44.46 and 44.86 for the control group and experimental group respectively. Further, the final YDS (The formal Proficiency Exam) score was 48 for the control group and 47 for the experimental group - the scores are almost the same. The mean for both groups during the first YDS exam is 1.282 while that of the ultimate YDS is 1.588. This shows an improvement of about 0.306 .

Today, autonomous learning has taken centre stage in the learning process in the universities and colleges. In this approach, the students play a larger role in learning compared to in the past when the teachers did. The current study has unveiled that the teacher in the contemporary learning environment only serves as a guide. Notably, autonomous learning has positively influenced the learning process, especially with the introduction of technology platforms, such as the internet. Further, autonomous learning has played a key function in the publishing of more books in the society. The aspect of self-regulated learning has necessitated the publishing of more books to enhance the learning process of the students. Thus, the approach has provided a platform for the enhancement of foreign language proficiency. 
Moreover, autonomous learning has spurred independence and created awareness among students (Lee, 2011). This study has revealed that the student-centred learning platform allows the students to accept responsibility and learn better. The study has defined the cognitive and meta-cognitive learning strategies as the most effective in autonomy learning. In addition, this study has revealed that the instructed foreign language approach is slightly more effective in developing language proficiency among the learners.

From the findings of this study, $97.4 \%$ of the participants were in agreement that teachers have a great role to play in enhancing the language proficiency of a learner. Regardless of the various efforts by the students to improve their language, it is observed that teachers have the role of ensuring that they comprehend what they have been taught. Essentially, this entails asking questions and employing assessment tests. The efficiency of answering questions as well as excellence in the assessment tests or exams are the basis of gauging a student's level of comprehension. This study further supports the idea that teachers play a role in ensuring that students know the 'what' and 'how' aspects of English.

This research affirms claims by Maier \& Richter (2014) that teachers' role is very important even in autonomous learning. From this study, a good majority (90.5\%) of the participants concurred that teachers have the responsibility of providing the methodologies for learning English. Moreover, the study helps in understanding that teachers have the role of making students excel in their examination. The study has also revealed that $89.7 \%$ of the participants were in agreement that teachers have the role of providing materials and notes that reflect what is to be covered in the exam. Consequently, this study provides the assurance that students greatly depend on the teachers in order to improve in language. However, meta-cognitive and mnemonic strategies of the SILL, as applied in autonomous learning, are essential to student's improvement in language.

\section{REFERENCES}

Chen, M.L., (2009). Influence of Grade Level on Perceptual Learning Style Preferences and Language Learning Strategies of Taiwanese English as a Foreign Language Learners. Learning and Individual Differences, 19(2), pp.304-308.

Cheng, H., (1996). Teachers' Role in an Autonomous Classroom. New Jersey. Willy John \& Sons.

Cox, D.R. and Reid, N., (1987). Parameter Orthogonality and Approximate Conditional Inference. Journal of the Royal Statistical Society. Series B (Methodological), pp.1-39.

Dmitrovic, J., Chan, S.C. and Chan, S.H., (2002). Analysis of Pesticides and PCB Congeners in Serum by GC/MS with SPE Sample Cleanup. Toxicology letters, 134(1), pp.253-258.Reid, R.C., Prausnitz, J.M. and Poling, B.E., 1987. The Properties of Gases and Liquids. 
Lee, C.K., (2010). An Overview of Language Learning Strategies. ARECLS, 7, pp.132-152.

Lai, Y.C., (2009). Language Learning Strategy Use and English Proficiency of University Freshmen in Taiwan. TESOL quarterly, pp.255-280.

Nel, C., (2008). 3 Learning Style and Good Language Learners. Lessons from Good Language Learners, p.49.

Oxford, R.L., (1994). Language Learning Strategies: An update. ERIC Clearinghouse on Languages and Linguistics, Center for Applied Linguistics.

Sun, F., (2010). Pedagogical Implications to Teaching English Writing. Journal of Language Teaching and Research, 1(6), pp.867-870.

Taylor, P., G (2000). Changing Expectations: Preparing students for Flexible Learning. The Inter-national Journal of Academic Development 5(2), 107-115.

Wang, Y.X., Zhang, C.L., Ruth, T.Y., Cho, H.K., Nelson, M.C., Bayuga-Ocampo, C.R., Ham, J., Kang, H. and Evans, R.M., (2004). Regulation of muscle fiber type and running endurance by PPAR $\delta$. PLoS Biol, 2(10), p.e294.

$\mathrm{Wu}$, Y.L., (2008). Language Learning Strategies Used by Students at Different Proficiency Levels. Asian EFL Journal, 10(4), pp.75-95.

Wenden, A., (1998). Learner Strategies for Learner Autonomy. Great Britain: Prentice Hall.

Zhe, W., (2009). A Contrastive Study of Chinese \& Western Learner Autonomy. USChina Foreign Language. London. Longhorn. 